Journal of Clinical Investigation

Vol. 41, No. 4, 1962

\title{
PATHOGENESIS OF THE COAGULATION DEFECT DEVELOPING DURING PATHOLOGICAL PLASMA PROTEOLYTIC ("FIBRINOLYTIC") STATES. III. DEMONSTRATION OF ABNORMAL CLOT STRUCTURE BY ELECTRON MICROSCOPY *
}

\author{
By NILS U. BANG, ANTHONY P. FLETCHER, NORMA ALKJAERSIG \\ AND SOL SHERRY \\ (From the Department of Medicine, Washington University School of Medicine, \\ St. Louis, Mo.)
}

(Submitted for publication July 13, 1961 ; accepted December 21, 1961)

As a result of recent studies, new concepts have arisen concerning the nature and pathogenesis of the coagulation anomaly encountered in spontaneously occurring and iatrogenically induced plasma proteolytic states $(1,2)$. Classically the hemorrhagic diathesis due to abnormal plasma proteolytic activity was attributed to hypo- or afibrinogenemia in combination with proteolytic destruction of a series of coagulation factors. When it became possible to induce and control a temporary proteolytic state through activation of the plasminogen-plasmin system by the administration of streptokinase intravenously (3), it was apparent that the classical hypothesis did not suffice to explain the coagulation defect which characteristically accompanied such treatment; the coagulation anomaly frequently occurred in the presence of normal or low normal plasma fibrinogen concentrations, and with insignificant changes in coagulation factors. The only requirement for the development of the syndrome was a sharp reduction of plasma fibrinogen, caused by proteolysis, and the extent of this reduction correlated closely with the severity of the observed defect (1).

Studies aimed at elucidating the phenomenon revealed that the digestion of fibrinogen, as it occurs in clinical states of hyperplasminemia, results in the liberation of a large molecular fragment. This abnormal fibrinogen derivative plays a key role in the development of the coagulation defect since it interferes with the clotting of fibrinogen and, as a result, significantly prolongs the one-stage prothrombin time and the thrombin

* This work was supported by a grant from the $\mathrm{Na}$ tional Heart Institute (H3745), United States Public Health Service, Bethesda, Md. clotting time $(1,2,4)$. Further studies have indicated that this large molecular fibrinogen derivative $\left(5.27 \mathrm{~s}_{20, w}\right.$, and estimated molecular weight of 83,000 ) interfered with the later stages of fibrinogen-fibrin conversion-i.e., the polymerization of fibrin monomer to fibrin-whereas the first step, the proteolytic conversion of fibrinogen to fibrin monomer by thrombin was unaffected (2). For this reason, we have termed the resulting coagulation anomaly "defective fibrin polymerization."

Since it was also observed that the clot which finally forms in the presence of fibrinogen breakdown products exhibits abnormal physical characteristics (the clot has a nonhomogenous, flocculent appearance and is more friable than the normal fibrin clot), we postulated that the coagulation anomaly of defective fibrin polymerization results in a clot with structural abnormalities.

The present electron microscopic study of the ultrastructure of clots formed in the presence of fibrinogen breakdown products was undertaken in an attempt to offer direct, anatomical, visual evidence that the fibrin gel may assume totally different characteristics when formed in the presence of these degradation products. It has tacitly been assumed in the past that once thrombin was generated in sufficient amounts in the presence of an adequate plasma fibrinogen concentration, the fibrin clot would always form in the same regular fashion and exhibit the same structural characteristics. The present data will serve to illustrate a new concept: abnormal plasma proteins or, in this particular instance, fragments of a normal plasma protein can alter the structural characteristics and presumably the functional capacity of a clot. Such structurally altered fibrin clots prob- 
ably contribute significantly to the hemorrhagic diathesis frequently seen in patients with "fibrinolytic" disorders.

\section{MATERIALS AND METHODS}

\section{Preparations}

Bovine fibrinogen was prepared according to the method of Blomback and Blomback (5). ${ }^{1}$ The material contained 99 per cent clottable tyrosine and was supplied as a 1.2 per cent solution in $0.3 \mathrm{M} \mathrm{NaCl}$. The stock was kept frozen in 1-ml aliquots, and dilutions to the desired concentrations were made immediately prior to each experiment.

In many experiments the bovine fibrinogen was trace labeled with $\mathrm{I}^{131}$, according to a previously described method (6). Since the iodination resulted in a slight loss of clottability, by thrombin, the preparations used in the present series of experiments contained 90 to 92 per cent clottable radioiodine.

Fibrinogen breakdown products (FBP) were prepared from the bovine fibrinogen stock by incubation with activator-free human plasmin prepared as previously described (7). Plasmin was added to $5 \mathrm{ml}$ of 1.2 per cent bovine fibrinogen to a final concentration of 3 caseinolytic units. The proteolytic degradation of fibrinogen and the appearance of biologically active FBP were recorded by repeated assays for "antithrombin activity" of the digest mixture (1).

Partial purification of the biologically active large molecular FBP was achieved by gel filtration on cross linked dextran gel columns according to Porath (8). Forty- to $50-\mathrm{ml}$ columns of Sephadex ${ }^{2}$ grade 50 and 75 gel were used; the Sephadex 75 gel proved to be the more effective for this purification. On the basis of ultracentrifugal data, the gel filtration resulted in an increase in the concentration of the biologically active FBP from 50 per cent in the original fibrinogen digest to 68 to 72 per cent, although significant contamination with another fairly large fragment $\left(3 \mathrm{~s}_{20, w}\right.$ component) was always present. The partial purification of the active component by this technique resulted in a proportionate increase in its "antithrombin activity."

Human plasma was citrated, outdated, pooled plasma kept frozen until used experimentally. Thrombin ${ }^{3}$ was used in concentrations of $10 \mathrm{U}$ per $\mathrm{ml}$ in isotonic saline. Streptokinase was in the form of Varidase. ${ }^{4} \epsilon$-Aminocaproic acid (EACA) 4 was chemically pure and chromatographically homogenous. Soybean trypsin in-

\footnotetext{
${ }^{1}$ Kindly supplied by Dr. Birger Blomback, Karolinska Institutet, Stockholm.

2 Obtained from Pharmacia Chem. Co., Uppsala, Sweden.

3 Parke, Davis Company, Detroit, Mich.

${ }^{4}$ Kindly supplied by Dr. J. Ruegsegger, Lederle Laboratories, Pearl River, N. Y.
}

hibitor $(\mathrm{SBTI})^{\bar{j}}$ was used at a concentration of $1 \mathrm{mg}$ per $\mathrm{ml}$.

Buffer was usually $0.1 \mathrm{M}$ borate at $\mathrm{pH} 7.6$; in a few instances $0.1 \mathrm{M}$ phosphate buffer, $\mathrm{pH} 7.6$, in 0.9 per cent saline was substituted. In most experiments buffers and other solutions were passed through $100-\mathrm{m} \mu$ pore size cellulosic ${ }^{6}$ filters to minimize particulate matter contamination of preparations employed for electron microscopy.

\section{Methods}

Fibrinogen was determined by the method of Ratnoff and Menzie (9), as previously modified (3), and thrombin clotting times by a technique previously described (3). In some instances it was necessary to determine thrombin clotting time in the absence of thrombin titration mixture. In our experience such assays are less reproducible than those performed by the original technique.

Preparation of fibrin films for visualization in the clectron microscope. A method was developed which permitted visualization of ultrathin fibrin films formed from purified fibrinogen and undiluted human plasma. Conventional copper wire mesh specimen grids covered by a polyvinyl Formvar membrane were attached around their circumference to bacteriological platinum wire loops. Thrombin in a final concentration of $1 \mathrm{C}$ per $\mathrm{ml}$ of clotting mixture was then added to purified fibrinogen or plasma. Immediately after the addition of thrombin, a drop of coagulation mixture was caught on a loop with a grid attached in such a way that the Formvar-covered surface of the grid was completely covered by the coagulation mixture. Before gel point, the loop with the droplet was rapidly blotted several times against a leaf of freshly cleaved mica and 95 to 98 per cent of the initial drop was blotted off against the intensely hydrophilic mica surface; this left only a very thin film of clotting mixture behind on the Formvar surface. These films were placed in a water-saturated atmosphere to prevent drying, and coagulation was allowed to proceed for 2 to 3 hours.

When coagulation was completed, the films were washed for 15 minutes in isotonic saline to free them of proteins which did not constitute an integral part of the clot. Fixation of the films was performed by immersing them in Palade's solution (10) of osmic tetraoxide at $\mathrm{pH}$ 7.5. The best films were obtained with 5 to 10 minutes' fixation. The films were then washed briefly in distilled water, dehydrated by brief exposure to increasing concentrations of ethyl alcohol, counterstained in a 1 per cent solution of phosphotungstic acid (PTA) in 95 per cent alcohol for 5 to 10 minutes, and finally washed for 2 hours in absolute ethyl alcohol. A few of the films were shadowcast with a platinum-palladium alloy at a shadow to height ratio of approximately 3 to 1 . The best preparations for shadowcasting were obtained by a slightly different and milder fixation technique: the films were exposed to osmic tetraoxide vapors for about 30 seconds

\footnotetext{
${ }^{5}$ Worthington Biochemical Corporation, Freehold, N. J.

${ }^{6}$ Millipore Filter Corporation, Bedford, Mass.
} 
instead of to osmic acid in solution; counterstaining in PTA was not employed.

Preparation of clots with abnormal structure. Several different types of abnormal clots were prepared:

1. Soybean trypsin inhibitor was added to preparations of FBP, of varying degrees of purity, to halt further proteolysis, and the mixture subsequently added in varying final concentrations to purified bovine fibrinogen. The final concentration of fibrinogen in the coagulation mixture was usually $50 \mathrm{mg}$ per $100 \mathrm{ml}$. Thrombin was added, a film was formed as described, and coagulation allowed to proceed for up to 24 hours. Since the structure of the final polymers did not seem to change from 3 to 24 hours after the addition of thrombin, clotting in most instances was allowed to proceed for only 3 hours.

2. Purified bovine FBP were added to human plasma and the films formed in the usual manner.

3. Undiluted human plasma was incubated with streptokinase (SK) prior to coagulation; the concentrations were chosen according to the titer of SK neutralizing antibodies of the plasma batch employed, as determined by our modification (3) of a previously described method (11). Incubation with SK was continued until the thrombin clotting time of the plasma had reached two to three times the normal values. EACA, a potent inhibitor of plasminogen activation (12), was then added to bring the state of increased plasma proteolysis to an end. Thrombin was added immediately thereafter, and films were formed in the usual fashion. As a control, EACA was added to normal plasma before the formation of the normal fibrin films.

4. Plasma from a patient suffering from carcinoma of the prostate with increased proteolytic ("fibrinolytic") activity and a severe hemorrhagic diathesis, ${ }^{7}$ was utilized to form fibrin films. The control plasma in these experiments was diluted to a final fibrinogen concentration of $125 \mathrm{mg}$ per $100 \mathrm{ml}$, identical to that present in the patient's blood.

Method for evaluating total amount of fibrin in specimen films. The use of trace labeled $\mathrm{I}^{131}$-fibrinogen en-

${ }^{7}$ The authors are indebted to Dr. W. E. Connor, State University of Iowa, for making available plasma specimens from this patient. The diagnosis of a coagulation disorder, secondary to hyperplasminemia, was established by previously described criteria (1).

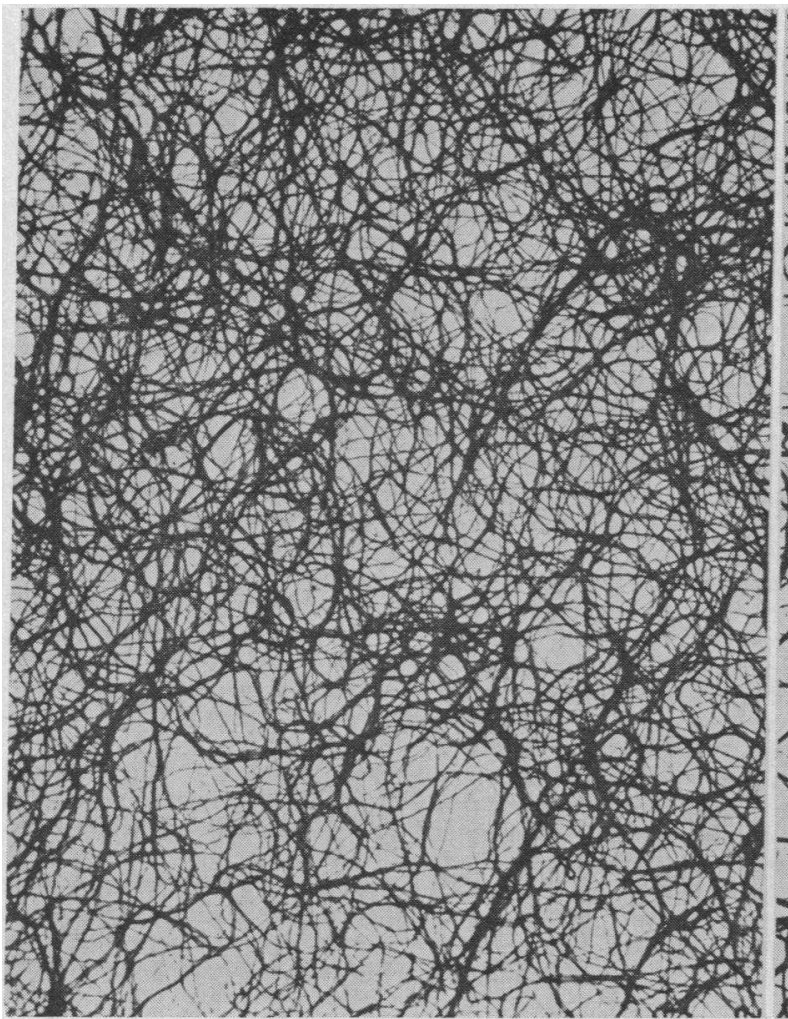

A

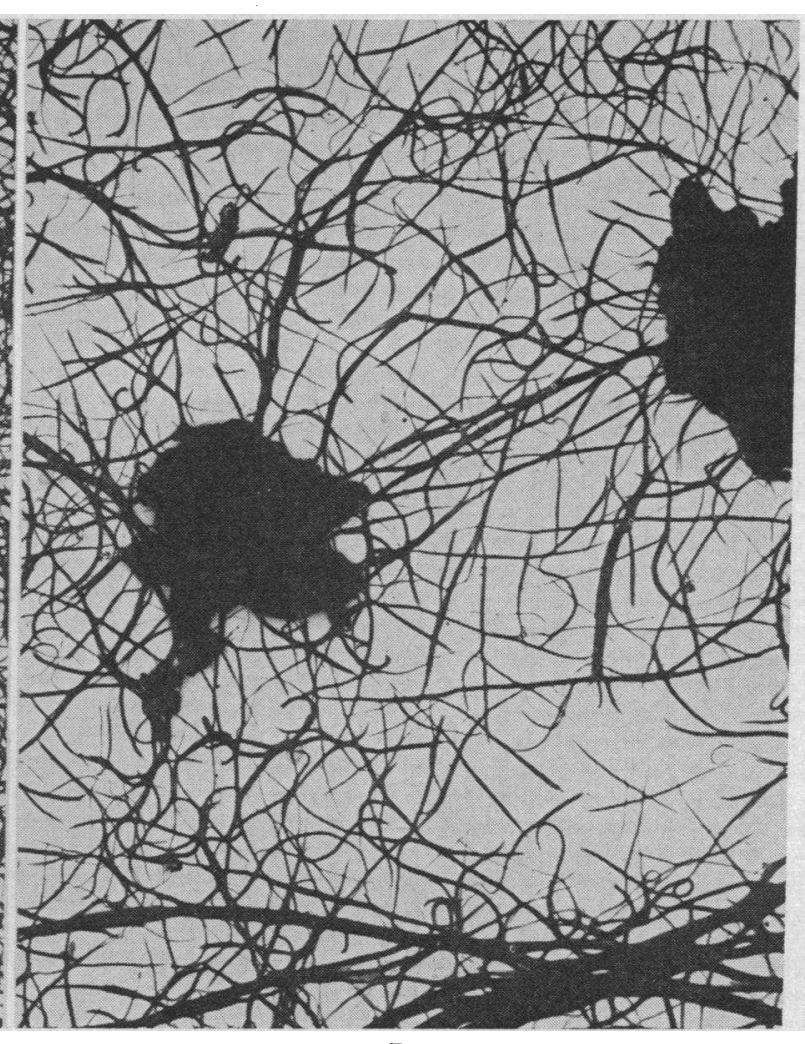

B

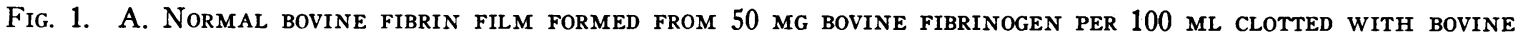
THROMBIN (FINAL MIXTURE 1 U PER ML). B. BOVINE FIBRIN FILM FORMED FROM 50 Mg FIBRINOGEN PER 100 ML, 5 MG HIGHLY PURIFIED FBP PER 100 ML, CLOTTED WITH THROMBIN (1 U PER ML IN THE FINAL MIXTURE). Three hours

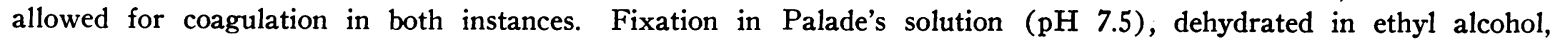
.counterstained with phosphotungstic acid (approximately $\times 2,500$ ). 


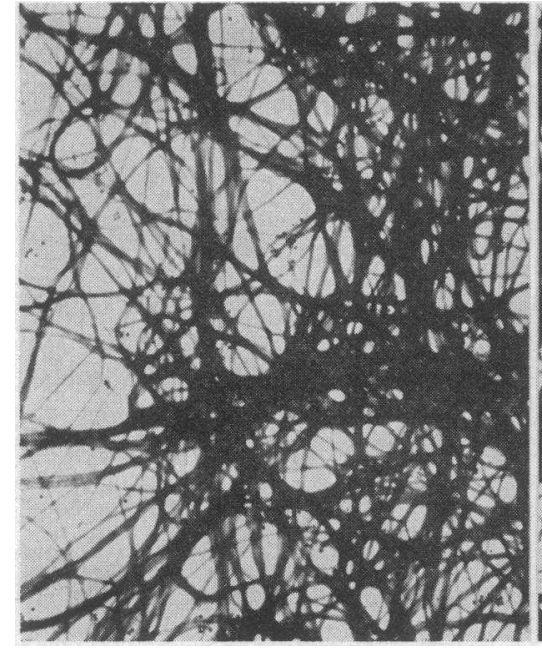

A

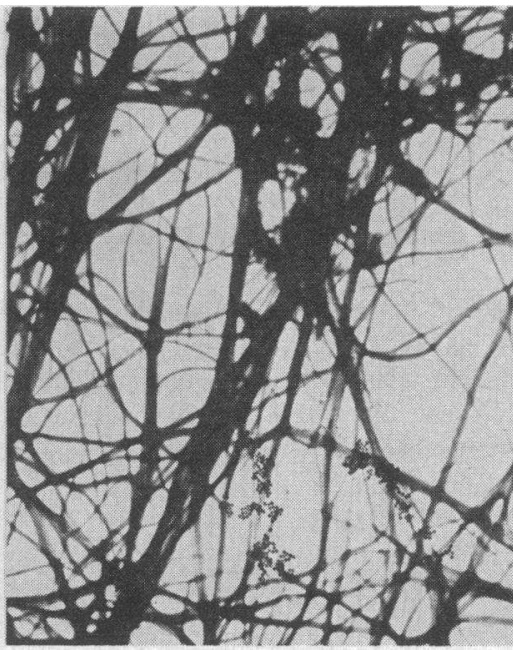

B

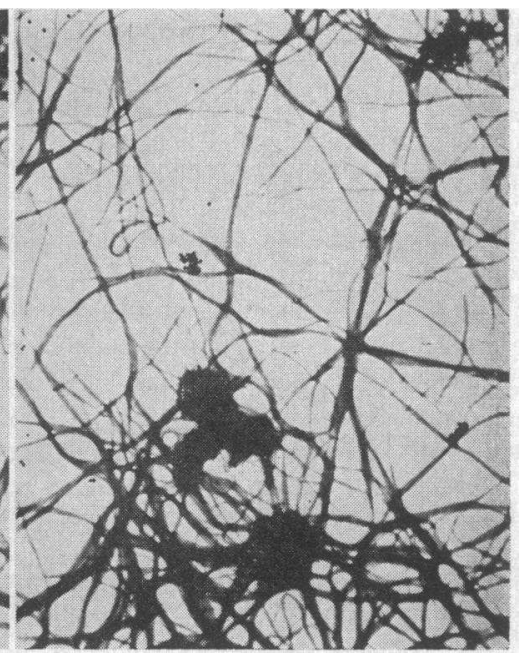

C

Fig. 2. A. BOVINE FIBRIN FILM FORMED FROM 50 Mg FIBRINOGEN PER 100 ML, 1 Mg CRUdE BOVINE FIBRINOGEN DIGEST PER $100 \mathrm{ML}$, AND $1 \mathrm{U}$ OF THROMBIN IN THE FINAL MIXTURE. B. Bovine FIBRIN FILM FORMED FROM 50 MG Fibrinogen PER 100 ML, 1 Mg partially pURIFied FBP PER 100 ML (SEe text), ANd 1 U thrombin. C. Bovine FIBRIN FILM FORMED FROM 50 MG FIBRINOGEN PER 100 ML, 1 MG HIGHLY PURIFIED FBP PER 100 ML, AND 1 U THROMBIN PER ML. Three hours allowed for coagulation in all three instances (approximately $\times 5,800$ ).

abled us to estimate the total amount of fibrin in a given film mounted on the supporting grid or, more accurately, allowed a rough quantitative estimate of the total number of fibrinogen molecules participating in the formation of normal and defective fibrin polymers. After fixation, staining, and dehydration of the films, the grid with fibrin film was removed from the original platinum loops and transferred to "clean" loops. The radioactivity of the loops was determined as previously described (13) with a statistical precision of 2 per cent. By varying the number of initial blottings of the films, it was possible to produce films of varying thickness, and, by making a sufficiently large number of films, it was possible to select matched pairs (i.e., films of normal and defective fibrin which exhibited identical radioactivity).

Electron microscopy. The fibrin films were examined

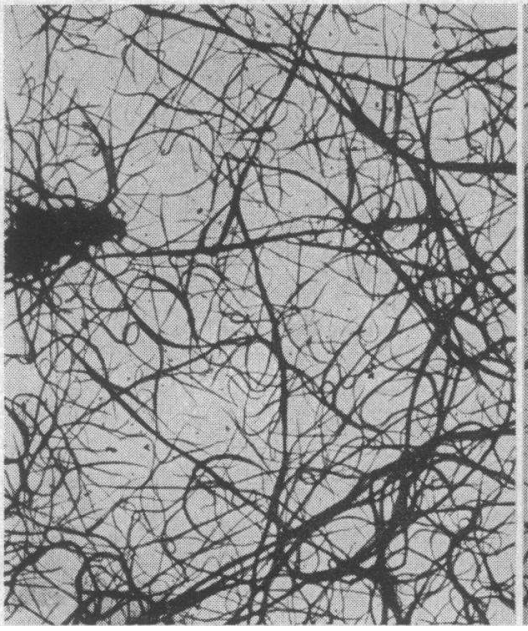

A

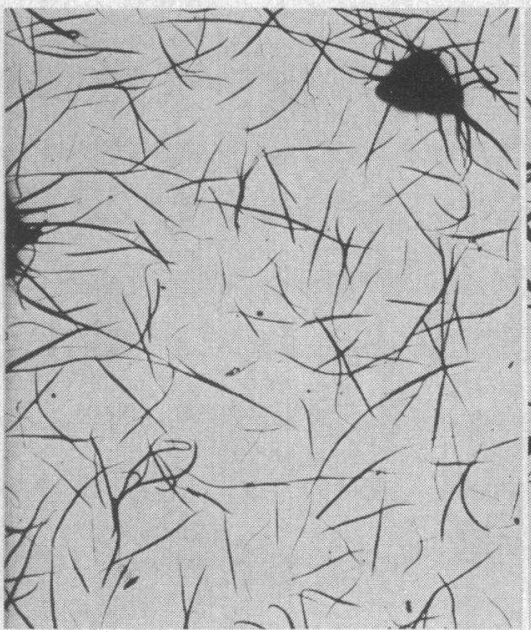

B

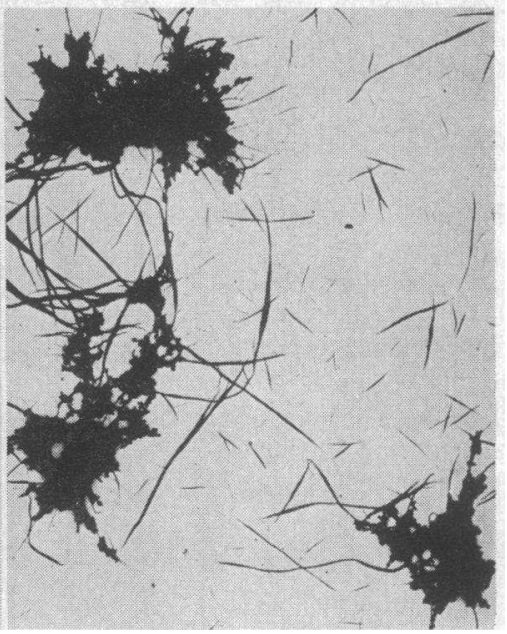

$\mathrm{C}$

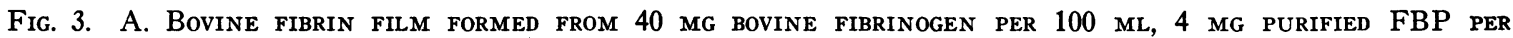
100 ML, AND 1 U OF THROMBIN PER ML. B. Bovine FIBRIN FORMED FROM 40 Mg FIBRINOGEN PER 100 ML, 40 MG PURIFIEd FBP PER 100 ML, AND 1 U THROMBIN. C. Bovine FIBRIN FILM FORMED FROM 40 Mg FIBRINOGEN PER 100 ML, 400 Mg PURIFIEd FBP PER $100 \mathrm{ML}$, AND 1 U THROMBIN. Twelve hours were allowed for coagulation. Specimen preparation as in Figure 1 (approximately $\times 2,200$ ). 
in electron microscopes, RCA models EMU 2 and EMU $3 \mathrm{~B}$ with a $25 \mu$ objective aperture. Electron micrographs were taken at an original magnification of 450 to 20,000 times and enlarged photographically as desired. Measurements of the protein structures were performed utilizing polystyrene latex spheres $^{8}$ as an internal

8 Dow Chemical Company, Midland, Mich. standard. The latex spheres used had a diameter of $880 \pm 80 \AA$.

\section{RESULTS}

I. Fibrin films formed from purified bovine fibrinogen and preparations of FBP. In Figure 1 is shown a low power electron micrograph of a

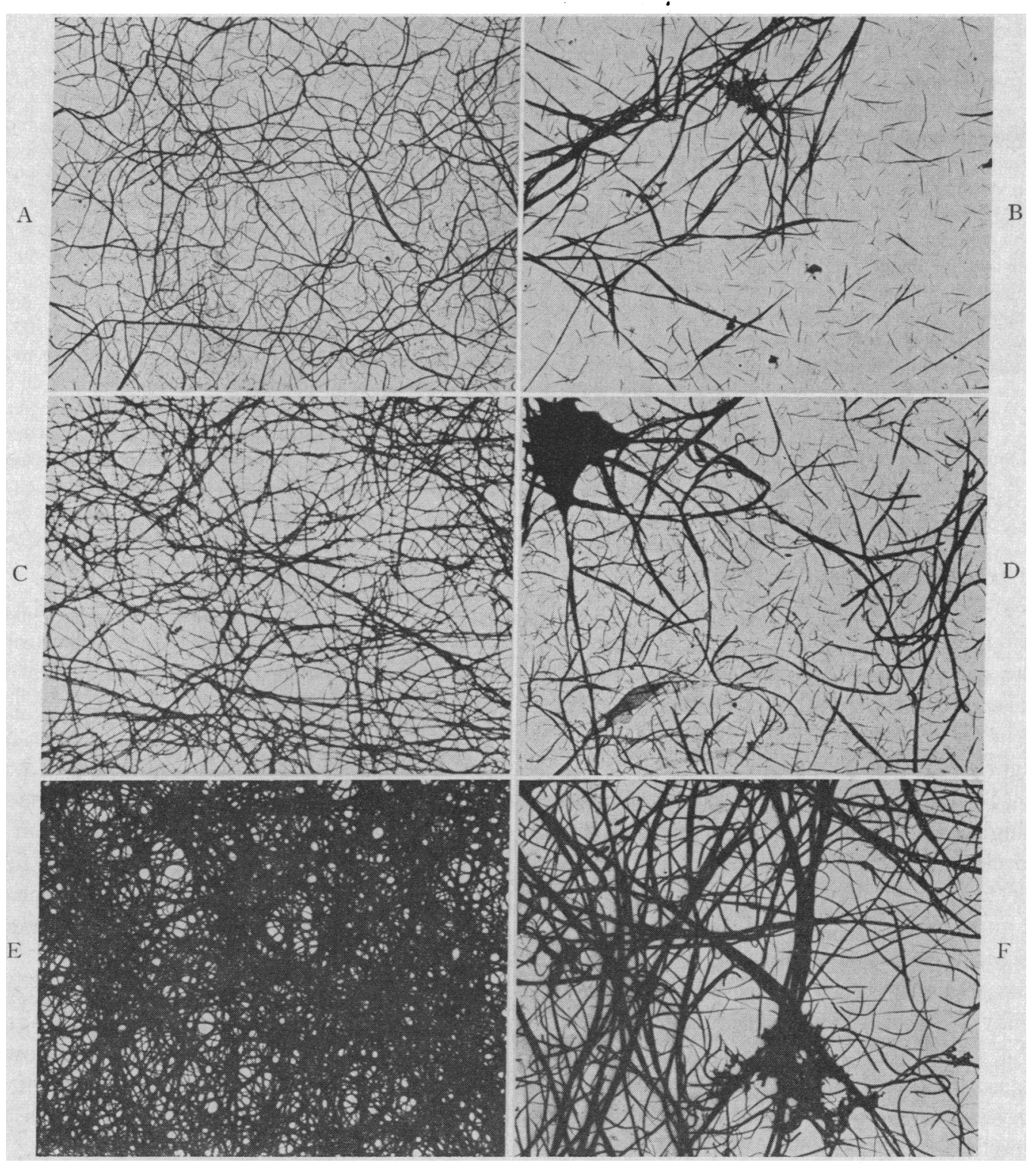

Fig. 4. Three pairs of NORMal and ABNormal fibrin FILMS; the two FILMS of Each PAIR EXHIBIT IDENTICAL RADIOACTIVITY. The top pair of grids ( $\mathrm{A}$ and $\mathrm{B}$ ) were loaded with $0.22 \mu \mathrm{g}$ fibrin, the middle pair (C and D) with $0.33 \mu \mathrm{g}$ fibrin, and the bottom pair ( $\mathrm{E}$ and $\mathrm{F}$ ) with $0.54 \mu \mathrm{g}$ fibrin. Normal control films formed from $50 \mathrm{mg}$ fibrinogen per $100 \mathrm{ml}$ and $1 \mathrm{U}$ thrombin per $\mathrm{ml}$ (grids $\mathrm{A}, \mathrm{C}$ and $\mathrm{E}$ ). Abnormal films formed from $50 \mathrm{mg}$ fibrinogen per 100 $\mathrm{ml}, 5 \mathrm{mg}$ highly purified FBP per $100 \mathrm{ml}$, and $1 \mathrm{U}$ thrombin (grids B, D, and F) (approximately $\times 1,850$ ). 


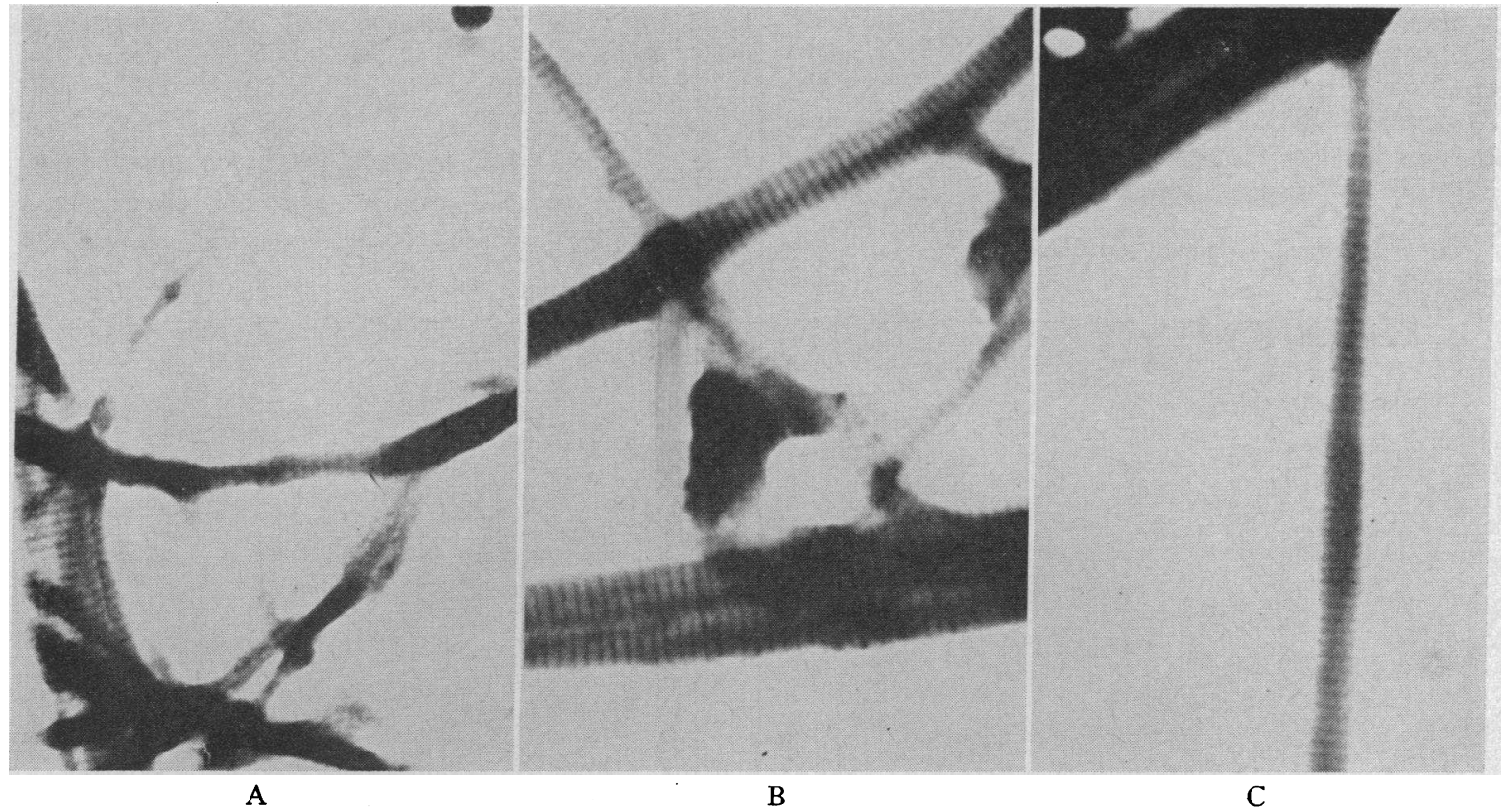

Fig. 5. High POWER electron micrographs SHOWING details of Fiber structure. A. Detail of normal fibrin film ( $50 \mathrm{mg}$ fibrinogen per $100 \mathrm{ml}, 1 \mathrm{U}$ thrombin). B. Detail of abnormal fibrin film (50 mg bovine fibrinogen per $100 \mathrm{ml}, 5 \mathrm{mg}$ purified FBP per $100 \mathrm{ml}, 1 \mathrm{U}$ thrombin). C. Detail from electron micrograph Figure 3C (approximately $\times 53,000$ ).

normal bovine fibrin film and one formed in the presence of purified FBP. The fibrinogen concentration was $0.5 \mathrm{mg}$ per $\mathrm{ml}$ in both instances; the final concentration of FBP was $0.05 \mathrm{mg}$ per $\mathrm{ml}$. The picture of the normal fibrin polymer differs in no respect from that described by other investigators utilizing principally similar techniques (14-16). In sharp contrast to the homogenous highly organized regular network of the normal clot, the defective fibrin clot is characterized by large nonfibrous aggregates built into a sparse and highly disorganized network.

A typical experiment illustrated in Figure 2, provides evidence for the specificity of the high molecular FBP fragment in inducing the abnormal clot structure. The fibrinogen concentration was again kept at $0.5 \mathrm{mg}$ per $\mathrm{ml}$ in each of three clotting mixtures. All three clotting mixtures contained $0.01 \mathrm{mg}$ per $\mathrm{ml}$ of $\mathrm{FBP}$ as determined by the tyrosine assay. In mixture 1 (Figure 2A) the FBP was a crude preparation and no attempts had been made to isolate the large molecular components of the digest. The thrombin clotting time for this mixture was 18 seconds as compared to a time of 15 seconds for the same concentration of fibrinogen without FBP added. The FBP in mixture 2 (Figure 2B) had been passed through a 10-ml Sephadex 50 column and resulting purification of the large molecular FBP was not impressive. The thrombin clotting time for mixture 2 was 22 seconds. The FBP in mixture 3 (Figure 2C) was purified on a Sephadex 75 column and prolonged the thrombin clotting time for the mixture to 43 seconds. It is evident from Figure 2 that the severity of the defect in the final clot structure increases with increasing purification of the large molecular FBP added to the coagulation mixture.

The effect of a wide range of concentrations of purified FBP was studied; the results are illustrated in Figure 3 which displays three low power electron micrographs from this series of experiments. The three coagulation mixtures (micrographs left to right) all contained $40 \mathrm{mg}$ fibrinogen per $100 \mathrm{ml}$ and FBP added to a final concentration of 4,40 , and $400 \mathrm{mg}$ per $100 \mathrm{ml}$, respectively. Mixture 1 clotted 42 seconds after the addition of thrombin. A solid gel was never formed in the two latter tubes but a flocculent precipitate was found in both instances after 2 to 
4 hours. Coagulation in these experiments was allowed to continue for 12 hours before the films were fixed and stained. It is clearly demonstrated from the electron micrographs in Figure 3 that increasing concentrations of FBP in the coagulation mixture will result in larger, more numerous nonfibrous aggregates and a concomitant decrease in the number of fibers in the fibrin film.

In Figure 4 are shown the results of a series of experiments, involving the use of $\mathrm{I}^{131}$-labeled fibrinogen, which demonstrate that the findings, previously described, are independent of the total amount of fibrinogen incorporated into the clot. Normal fibrin films were formed from a solution of $50 \mathrm{mg}$ fibrinogen per $100 \mathrm{ml}$, defective films from a mixture of $50 \mathrm{mg}$ fibrinogen per $100 \mathrm{ml}$, and $5 \mathrm{mg}$ uniabeied FBP per $100 \mathrm{ml}$. The montage of 6 low power electron micrographs is arranged in pairs of normal and defective fibrin films. The two films of each pair exhibit almost identical radioactivity: expressed as fibrinogen per grid, the top pair contained 0.216 and $0.217 \mu \mathrm{g}$, respectively; the middle pair 0.330 and $0.324 \mu \mathrm{g}$, respectively; and the lower pair 0.531 and 0.557 $\mu \mathrm{g}$, respectively. The pairs are arranged in order of increasing density of the films.

With increasing amounts of fibrin in the normal film, the number of fibers and the width of individual fibers increase, as noted previously by other investigators (16), but at all levels of density the normal fibrin clot maintains its regular and highly organized structure. With increasing

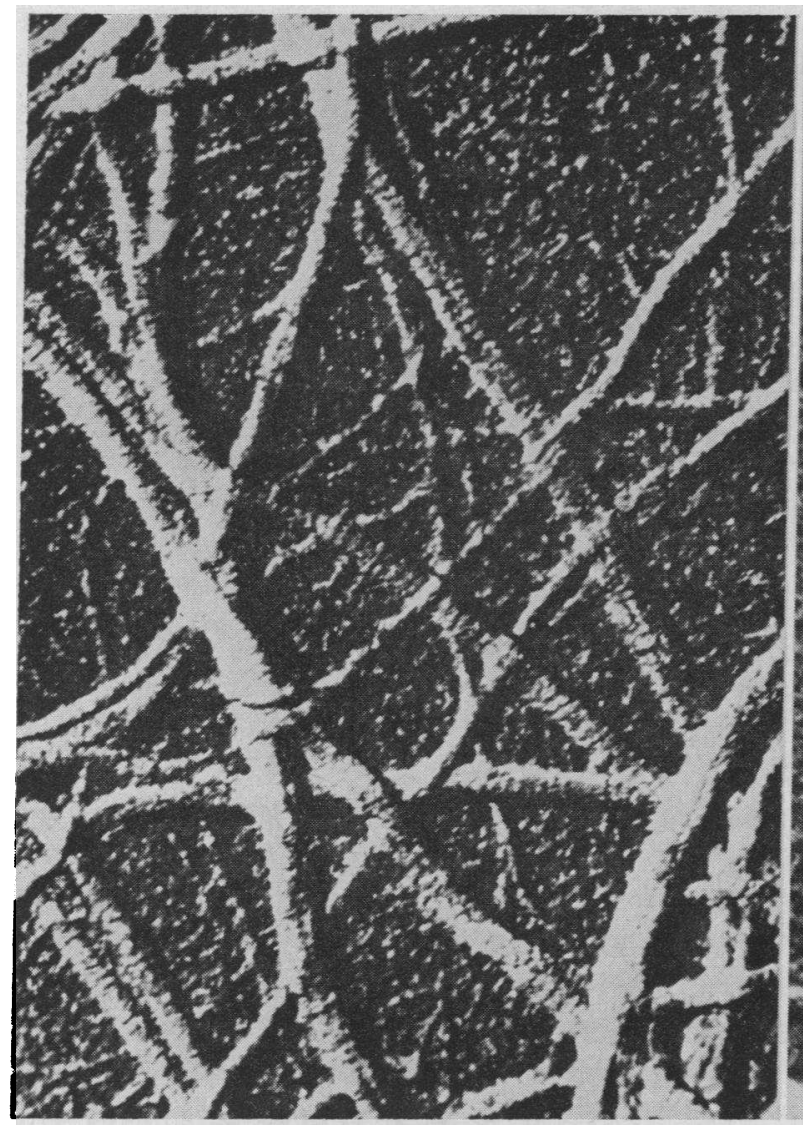

A

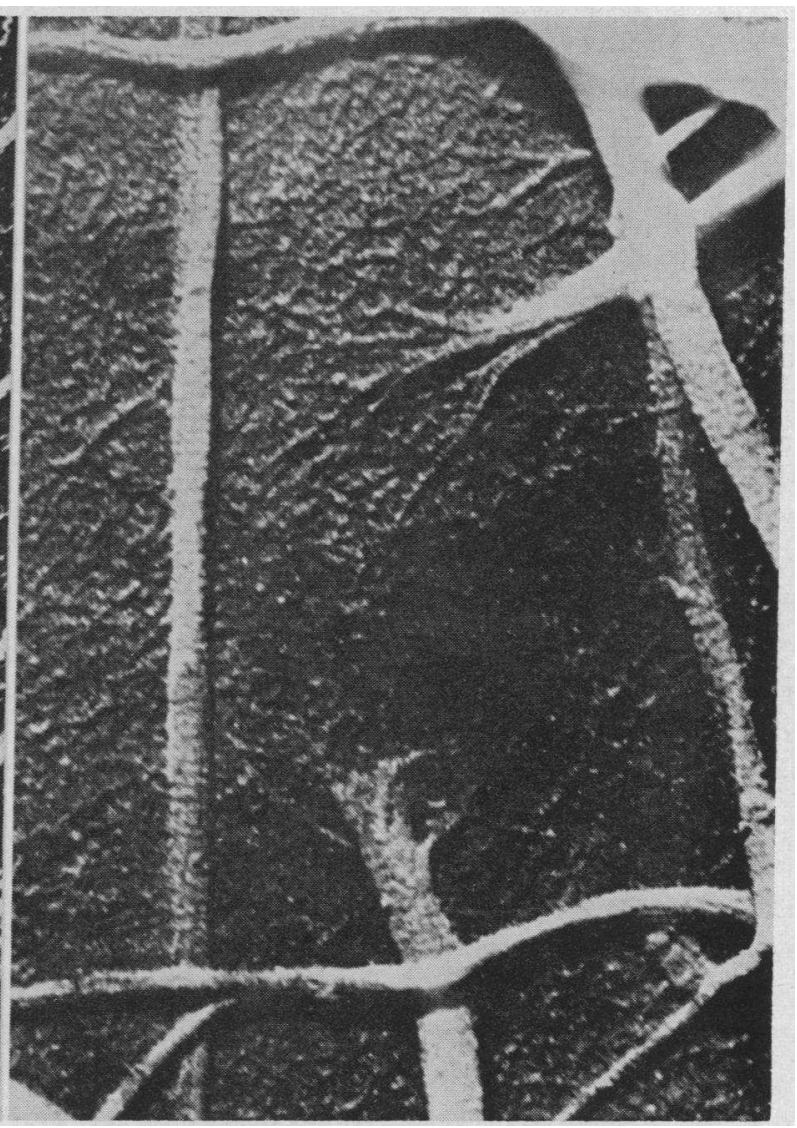

B

Fig. 6. High POWER ELECTRON MICROGRAPHS OF NORMAL AND ABNORMAL FIBRIN FILMS DEMONSTRATING CHARACTERISTIC “FRAYED ROPE" APPEARANCE OF FIBERS IN ABNORMAL POLYMERS. A. Normal fibrin film (50 mg fibrinogen per $100 \mathrm{ml}, 1 \mathrm{U}$ thrombin per $\mathrm{ml}$ ). B. Abnormal fibrin films (50 mg fibrinogen per $100 \mathrm{ml}, 5 \mathrm{mg}$ purified FBP per $100 \mathrm{ml}, 1 \mathrm{U}$ thrombin per $\mathrm{ml}$ ). Fixation: Thirty seconds' exposure to osmium tetroxide vapors. Dehydration in ethyl alcohol. Shadowed with $\mathrm{Pt}-\mathrm{Pd}$ alloy (60 per cent $\mathrm{Pt} ; 40$ per cent $\mathrm{Pd}$ ) at a shadow to height ratio of approximately $3: 1$ (approximately $\times 54,000$ ). 


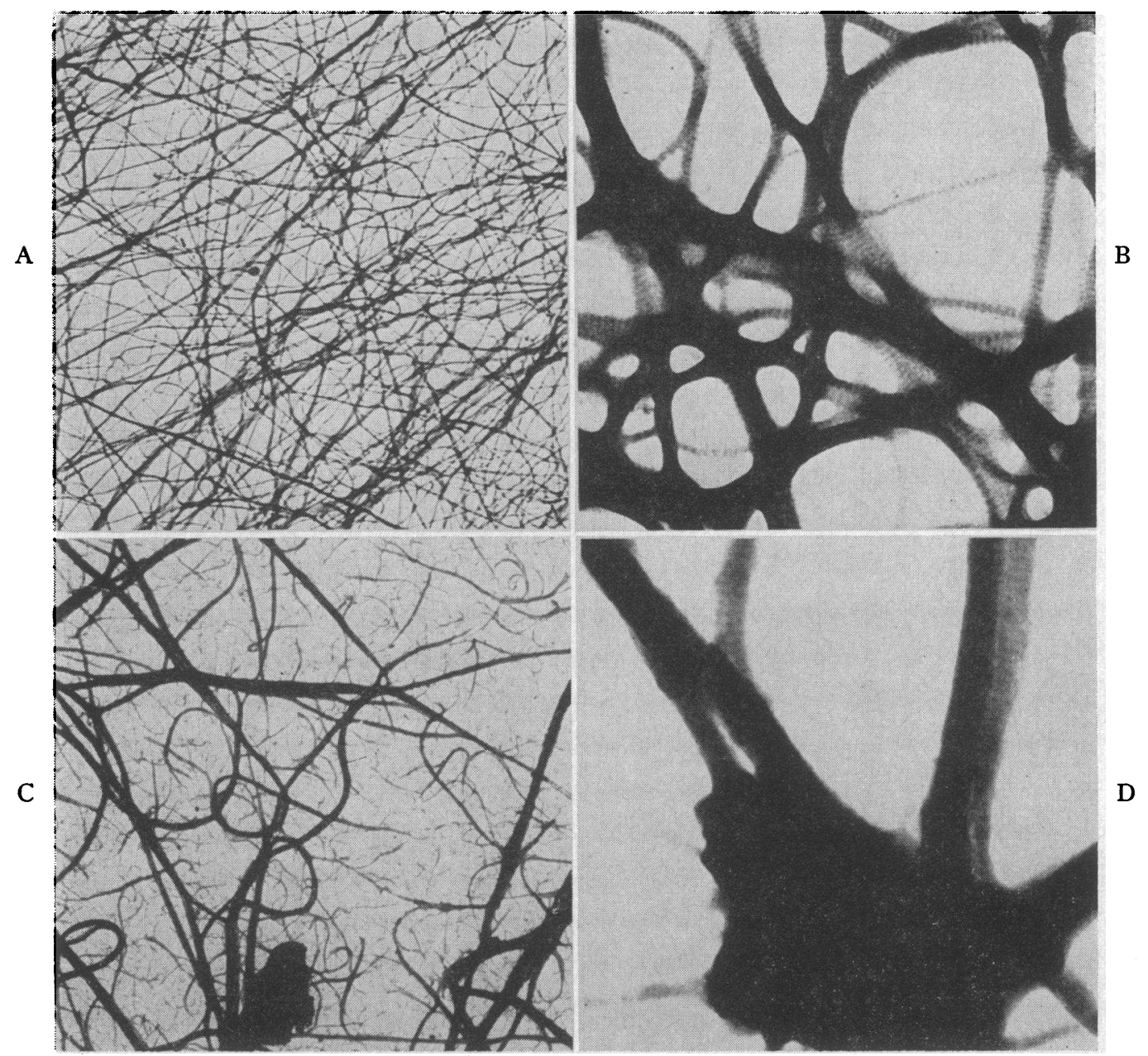

Fig. 7. (TOP ROW) LOW POWER (A) AND HIGH POWER (B) ELECTRON MiCROGRAPHS OF FIBRIN FILMS FORMED FROM UNDILUTED HUMAN PLASMA. (BOTTOM ROW) FIBRIN FILM FROM HUMAN PLASMA WITH PURIFIED BOVINE FBP ADDED TO A FINAL CONCENTRATION OF 40 Mg PER $100 \mathrm{ML}$. Low power survey micrograph (C) and high power micrograph (D) (approximately $\times 5,400$ and $\times 41,000)$.

fibrin concentrations in the abnormal film the over-all number of fibers and the fiber width similarly increase but the network remains highly disorganized throughout and nonfibrous aggregates are a constant feature at all film densities.

Attempts were made to elucidate the basic nature of these striking changes through a study of the periodicity of individual fibers of normal and defective clots at high magnification. In Figure 5 are shown three electron micrographs of a few fibrin fibers, all magnified approximately 53,000 times. Figure 5A shows fibers from a normal film; Figure $5 \mathrm{~B}$ is from a film of a coagulation mixture containing $50 \mathrm{mg}$ fibrinogen per $100 \mathrm{ml}$ and $5 \mathrm{mg}$ FBP per $100 \mathrm{ml}$; and Figure $5 \mathrm{C}$ shows a detail of a previous preparation (Figure 3C) containing $40 \mathrm{mg}$ fibrinogen per $100 \mathrm{ml}$ and $400 \mathrm{mg}$ FBP per $100 \mathrm{ml}$. The periodic structure of the fibrin fiber previously noted by other investigators $(14,15)$ is clearly demonstrated in all three pictures. This periodicity was found to be $235 \pm 30 \AA$, in good agreement with previous reports $(14,15)$; no difference in periodicity could be established between the fibers of the normal and abnormal clots.

In Figure 6 are shown two high power electron micrographs of shadowcast preparations of a normal and defective fibrin clot. The figure will 
serve to illustrate the one fiber anomaly which was constantly encountered in the defective clot; i.e., the blind ends of the fibers of the defective clot have a characteristic "frayed rope" appearance (Figure 6B). In contrast, normal fibers failing to make contact with other fibers characteristically showed pointed tapering ends.

II. Fibrin films formed from human plasma rendered "pathological" in vitro. In Figure 7 is shown a montage of four electron micrographs; the top row (Figures 7A, B) represents low and high power micrographs of fibrin from undiluted normal human plasma. The human plasma fibrin fiber cannot be distinguished from that formed from purified bovine fibrinogen, and the periodic structure of the fibers is identical in the two situations. The bottom row (Figures 7C, D) shows two electron micrographs of fibrin from human plasma (fibrinogen concentration $280 \mathrm{mg}$ per 100 $\mathrm{ml}$ ) with $40 \mathrm{mg}$ per $100 \mathrm{ml}$ of purified bovine FBP added. Both the low power survey micrograph and the high power micrograph demonstrate clearly that abnormal clots formed in this manner exhibit all the characteristics of the films formed from purified proteins.

In Figure 8 are illustrated the results of an in vitro experiment designed to elucidate the effect of a temporary proteolytic state, as seen clinically in patients with fibrinolytic disorders and in pa- tients undergoing treatment with thrombolytic agents. All three films were formed from the same batch of pooled human plasma. The left micrograph (Figure 8A) represents a normal control, and was formed from plasma with EACA added to a final concentration of $0.1 \mathrm{M}$. The center and right micrographs were formed from plasma which had been incubated with SK prior to coagulation.

Figure $8 \mathrm{~B}$ is a film from plasma incubated with $5 \mathrm{U} \mathrm{SK}$ per $\mathrm{ml}$ for 1 hour. Since the level of SK-neutralizing antibody of the plasma used in this experiment was $10 \mathrm{U}$ per $\mathrm{ml}$, the $\mathrm{SK}$ was completely inhibited by antibody; no fibrinolytic activity developed, and the thrombin clotting time of the sample remained within normal limits. No abnormalities in clot structure are apparent.

Figure 8C was formed from plasma incubated with $50 \mathrm{U} \mathrm{SK}$ per $\mathrm{ml}$ for 0.5 hour. This treatment resulted in the development of an active fibrinolytic and proteolytic state; the fibrinogen level fell from 280 to $210 \mathrm{mg}$ per $100 \mathrm{ml}$, and the thrombin clotting time was prolonged from 12.5 to 36.0 seconds. The fibrin film (Figure $8 \mathrm{C}$ ), formed after the addition of EACA to stop the enzymatic activity in the specimen, reveals striking abnormalities.

The findings illustrated in Figure 8 demonstrate that neither the addition of EACA, nor the

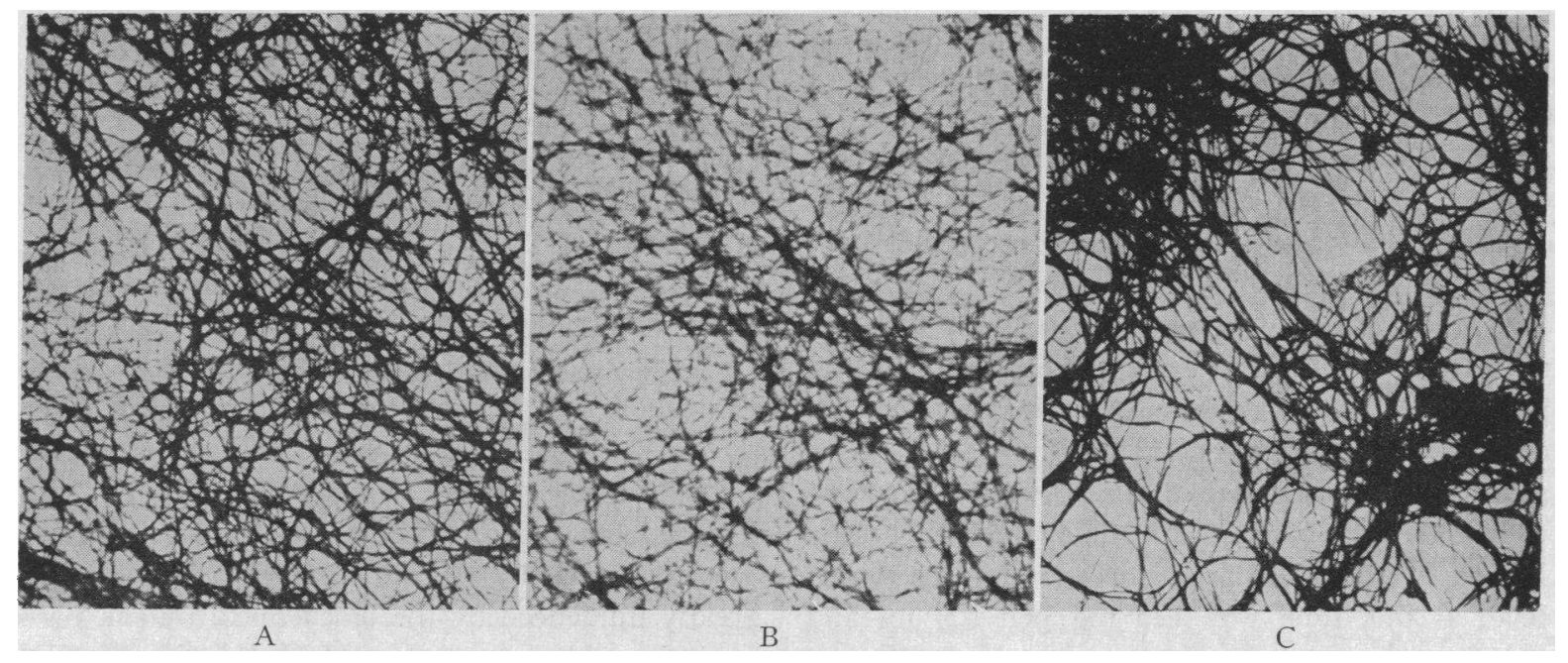

Fig. 8. A. Fibrin film from human plasma with EACA added to a final concentration of 0.1 M. B. FiBRIN FILM FROM SAME HUMAN PLASMA INCUBATED WITH5 U OF SK PER ML FOR 1 HOUR PRIOR TO COAGULATION. EACA added to a final concentration of $0.1 \mathrm{M}$. C. Fibrin FILm fRom SAME PLASma incubated with $50 \mathrm{U}$ of SK FOR 0.5 HOUR PRIOR TO COAGUlation. EACA added to a final concentration of $0.1 \mathrm{M}$. All three samples clotted with bovine thrombin, $1 \mathrm{U}$ per $\mathrm{ml} ; 5$ hours allowed for coagulation (approximately $\times 2,500$ ). 


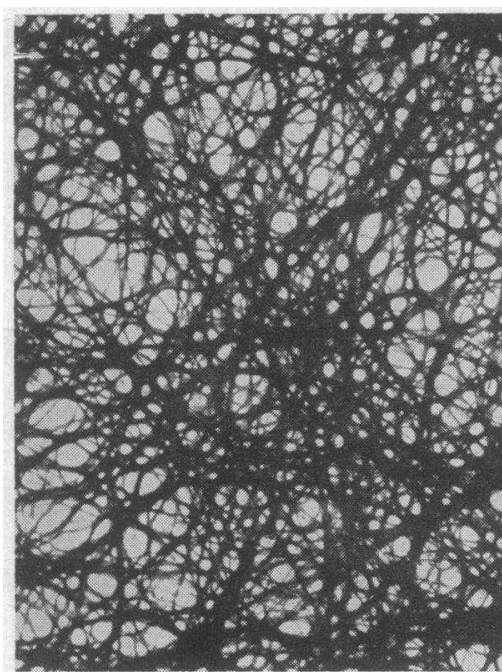

A

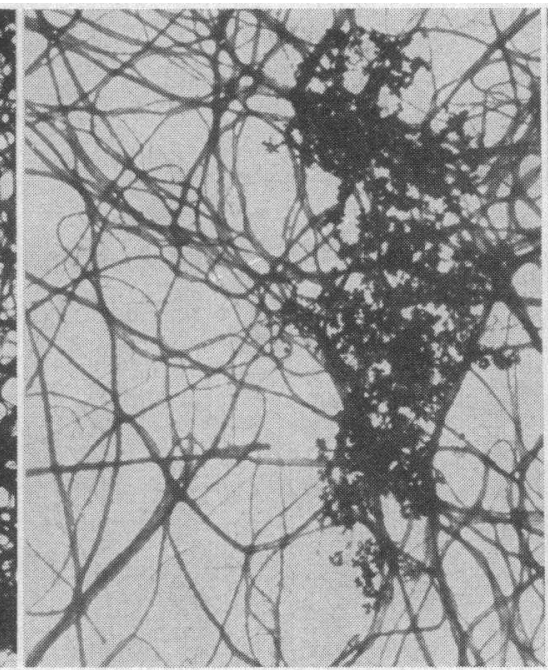

B

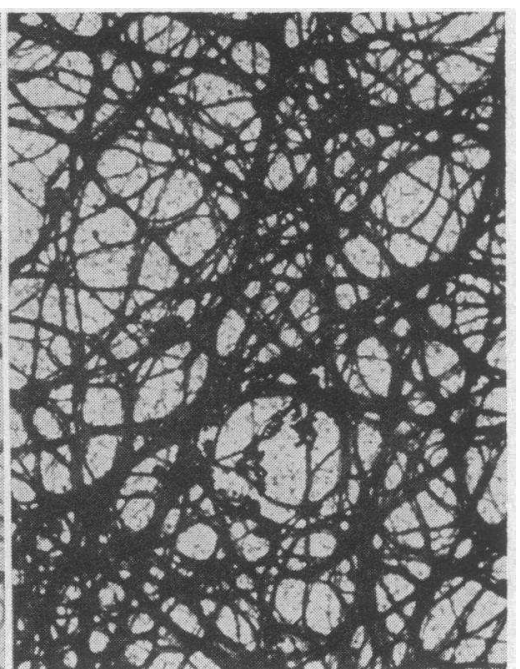

C

Fig. 9. A. Fibrin film from control plasma diluted to a final fibrinogen concentration of 125 mg per 100

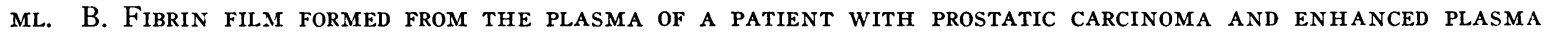
proteolytic activity obtained before treatment with EACA. C. Fibrin film from plasma of same patient AFTER EACA tREATMENT. The fibrinogen concentration in the pretreatment sample was $125 \mathrm{mg}$ per $100 \mathrm{ml}$ and 150 $\mathrm{mg}$ per $100 \mathrm{ml}$ in the post-treatment sample. Coagulation with thrombin, $1 \mathrm{U}$ per $\mathrm{ml} ; 6$ hours allowed for coagulation (approximately $\times 5,600$ ).

addition of SK in insufficient amount, alters the normal fibrin clot structure, but that an active fibrinolytic and proteolytic state induced by the addition of appropriate amounts of SK, specifically results in a defective fibrin structure with all the characteristics previously described.

III. Fibrin films formed from spontaneously occurring "pathological plasma." Finally, in Figure 9 is shown a series of electron micrographs which demonstrate a counterpart in clinical pathology to the in vitro observations previously described. Figure 9A shows a control film prepared from normal plasma, diluted to give a final fibrinogen concentration of $125 \mathrm{mg}$ per 100 $\mathrm{ml}$. Figures $9 \mathrm{~B}$ and $9 \mathrm{C}$ are fibrin films from the plasma of a patient suffering from prostatic carcinoma with "pathological fibrinolysis" and a severe hemorrhagic diathesis. Figure $9 \mathrm{~B}$ was prepared from a plasma sample obtained at the height of the bleeding disorder; the fibrinogen level at this time was $125 \mathrm{mg}$ per $100 \mathrm{ml}$ and the thrombin clotting time prolonged to $19 \mathrm{sec}$ onds. The striking differences between the normal control and the defective film prepared from the patients' plasma is readily apparent. After the oral administration of EACA, the patient's "fibrinolytic disorder" subsided; with the cessation of bleeding, another plasma specimen was obtained (Figure 9C). Partial correction of the defect is seen; a few nonfibrous aggregates are still present but the fibrous network is now much more regular and organized than in the pretreatment specimen.

\section{DISCUSSION}

The clotting of fibrinogen by thrombin, whether the fibrinogen is present in plasma or as a pure component, involves first the splitting off of fibrinopeptides $\mathrm{A}$ and $\mathrm{B}$ with the formation of fibrin monomer, and second a complex and relatively poorly understood phase of monomer polymerization with the subsequent formation of a gel or clot. Despite intensive biochemical and biophysical investigation (17), many details concerning this reaction are obscure, although it has long been recognized that the final clot structure is greatly influenced by the biochemical milieu, particularly with respect to $\mathrm{pH}$ and ionic strength $(18,19)$, in which clotting occurs. Moreover, electron microscopic study has yet failed to provide an entirely satisfactory basis for clot structural configuration explainable on a molecular 
basis $(14,15,20)$. Nevertheless, clots formed in thin layer sheet from either purified fibrinogen or from plasma in a milieu of defined physicochemical properties exhibit, when examined by electron microscopy, a consistent structural pattern. Four normal features are particularly important: 1) such clots exhibit conspicuous striations, remarkable for their regular periodicity $(14$, 15) ; 2) branching and bonding of individual fibers is so frequent that a regular continuous meshwork structure is visible even if initial fibrinogen concentration was low $(18) ; 3$ ) although the range of fiber width in individual clot preparations is considerable, the width frequency distribution is sufficiently regular to afford a characteristic appearance to the preparation, and individual fiber width in the absence of branching is relatively constant so that tapered or irregular fibers are few; and 4) if the clots are well washed during specimen preparation, aggregates of undifferentiated material (of any considerable size) are seldom observed adherent to the clot structure. These normal appearances afford a basis for the study of the abnormal, even though some of the normal clot characteristics are necessarily subjectively determined.

Moreover, the elegant electron microscopic studies of Porter and Hawn (21) on the different serial changes of clot formation provide further data by which variations from the normal may be evaluated. These investigators described a continuous series of events: the early appearance of small needle-like structures formed from protofibrils; the increase of size in these structures as clotting progressed; lateral aggregation of the unit fibers along the long axis and particularly by lateral association at the tapering ends of the unit fibers; the formation of compound fibers; the development of branching by unit fiber aggregation with more than one compound fiber; and finally the appearance of the formed clot in which unit fibers retain their identity within the strands and the striking appearance of cross striations develop.

However, interpretation of clot structural abnormalities displayed by electron microscopy is hindered by limitations inherent in specimen preparation, nonhomogeneity of specimen grids, and by lack of knowledge concerning the basis for the normal structural arrangement. Despite the development of two ingenious theories $(15,20$,
$21)$, there is uncertainty as to the precise molecular arrangement by which fibrin monomer units polymerize to produce cross striations with regular periodicity. These striations, an obvious and striking feature in technically adequate micrographs, would appear to represent the molecular subunit of structure; adequate explanation for their appearance on the basis of molecular arrangement and alignment would greatly facilitate interpretation of micrographs. The problem of interpretation is further complicated by the fact that fibrin clots are inherently three dimensional structures, but for the purposes of microscopic examination, they have to be prepared in what is essentially a two dimensional manner (i.e., as thin film preparations). Whether artifactual appearances result from such a procedure cannot yet be determined. Errors may also arise because of fibrin nonhomogeneity, which introduces a subjective element into field sampling. Although great care was taken during this investigation, many grids and fields being inspected before selecting (as far as possible) representative areas for detailed study and photography, some subjective bias may have been introduced.

Nevertheless, as indicated previously, definite and identifiable appearances characterize the "normal" clot examined by electron microscopy. A1tered molecular configuration would be expected to alter these "normal" characteristics and, as displayed in the text figures, obvious alterations in clot structure were demonstrated.

It could be predicted from investigation of the biochemical aspects of the coagulation defect accompanying enhanced plasma proteolytic activity (2) that morphological alterations of fibrin clots, formed in the presence of fibrinogen proteolysis products, would exist at the molecular level. However, the exact nature of the changes could not be predicted. With the aid of electron microscopy, it has been possible to confirm the prediction, to characterize the morphological defect, and to formulate a more definite hypothesis concerning the mechanism by which interaction of fibrin monomer and fibrinogen proteolysis products produces the abnormal gel.

The purely biochemical and biophysical approach to the problem (2) suggested at least three theoretical possibilities to explain the mechanism of defective fibrin polymerization. 
1. The forces of intermolecular attraction, involved in polymerization, might be diminished as a consequence of net charge differences between fibrin monomer and the proteolysis products. Although the biophysical evidence (2) suggested that the magnitude of the component (fibrin monomer and the $5.27 \mathrm{~s}_{20, w}$ fibrinogen fragment) differences were small, the possibility that net charge differences at the complex polymer stage might be greater could not be dismissed. Such differences could result in the formation of an inadequate gel, due to both diminished fiber formation and to diminished lateral aggregation of unit fibers.

2. The abnormal polymer formed by union of fibrin monomer and the large molecular weight fibrinogen fragment might lack a sufficiency of linkage sites and, being incorporated in the fibrils, diminish their production and inhibit lateral aggregation.

3. The abnormal polymer might aggregate with normal polymers or itself, or both, in a random manner, resulting in total structural disorder of some parts of the fibrin clot but structural integrity of other parts. Because effective monomer concentration would be diminished, further secondary abnormalities might complicate the appearance.

These hypotheses are not mutually exclusive; indeed it would be difficult to distinguish between the first and second hypotheses on purely morphological grounds. The third hypothesis is different from the others only in a quantitative respect, for the biochemical and biophysical findings (2) indicate that defective fibrin polymerization may occur with a very low ratio of fibrinogen proteolysis products to monomer-a finding indicating that some structural units are almost certainly normally constituted even in the "abnormal" clots.

The differences between the normal clots and those with defective fibrin polymerization may be summarized as follows. 1) The regular fibrin network characteristic of the normal clot is altered, for the abnormal clot shows a much less tightly knit meshwork with blindly terminating fibers (shown in high power view, Figure 6); these blindly terminating fibers, while infrequent in the normal clot, occur with conspicuous frequency in the abnormal one. 2) There is evident disturbance in compound fiber width in the ab- normal clots; the fibers tend to be either large or small and exhibit an unusual tendency to vary in width, whereas the normal shows a much narrower type distribution and structurally, except where branching, are more even in width. 3) Stellate aggregates of large size are frequently present, especially at fiber junctions in the abnormal clots (high power view, Figure 7); these are infrequently seen in normal clots, but when observed are much smaller and less regularly associated with fiber junctions. 4) The last feature, the blindly terminating or, more characteristically, the tapered fiber that terminates blindly in a very sparse network, seen especially in Figure 3, but also occurring in association with the fragmentary networks in other figures, is of considerable interest. As shown by Porter and Hawn (21), the appearance is characteristic of clot formation at an intermediate stage before completion of polymerization, and the presently recorded appearances simulate to a remarkable degree the micrographs published by these authors.

All these findings suggest that abnormal polymers, formed by union of fibrin monomer and the $5.27 \mathrm{~s}_{20, w}$ fibrinogen fragment are incorporated, to some extent, into most of the fibers of the abnormal clots as well as into the undifferentiated aggregates, which appear as part of the abnormal clot structure. Such a hypothesis would be entirely consistent with the data so far discussed, and in fact appears to afford the only rational explanation suited to the findings.

On the other hand, cross striation periodicity measurements failed to reveal differences between normal and abnormal fibers, a finding at first sight contrary to the concept that the abnormal fibers had an altered molecular structure. However we would emphasize, in company with Hall (15), who observed a 20 per cent variation in cross striation periodicity measurements, that this measurement presents a number of difficulties and is not precise; serious errors may arise because of variations among fibers in their inclination to the focus plane, stretching during grid preparation, and sampling bias.

Furthermore, biochemical data (2) indicate that defective fibrin polymerization occurs and is important clinically (1) when a comparatively small proportion of the clot structure (below 10 per cent) consists of the abnormal fibrinogen prote- 
olysis product. Consequently, since the exact molecular configuration of the cross striation is not completely elucidated, it is conceivable and perhaps likely that incorporation of the abnormal fibrinogen proteolysis product in an amount suffcient to produce structural abnormalities in fibers, might not influence apparent striation periodicity to a detectable extent.

Perhaps the most important evidence concerning the nature of defective fibrin polymerization is that shown in Figure 4. Through the use of radioactive fibrinogen it was possible to match the three pairs of contrasting grids so that each normal and abnormal was loaded with exactly the same quantity of fibrinogen; the representative fields shown are comparable with respect to this important variable and vary only with respect to the addition of fibrinogen proteolysis products. The lowest fibrinogen concentration grids (Figures $4 \mathrm{~A}$ and $\mathrm{B}$ ) show many blindly terminating tapering fibers of uneven width with fusion failure of crossing fibers and no indication of lateral aggregation of the tapering ends; the next higher fibrinogen concentrations also show these features together with the formation of a large undifferentiated structureless aggregate; and the highest fibrinogen concentration is a particularly striking example of network structural disorganization.

Unfortunately the structural morphology of aggregate formation is not revealed by electron microscopy, but the indirect evidence would suggest that these aggregates represent complete structural disorganization; i.e., a gross exaggeration of the other abnormalities noted. This concept is supported by the fact that aggregate formation increases as the ratio of fibrinogen proteolysis products to fibrinogen was increased and that when defective fibrin polymerization is of gross degree, as judged by biochemical tests, total clot structural disorganization may be visualized macroscopically (2).

Finally, we interpret the morphological evidence to indicate that defective fibrin polymerization, of the type under discussion, results from incorporation of the $5.27 \mathrm{~s}_{20, \mathbf{w}}$ fibrinogen fragment, complexed with units of fibrin monomer, into elemental structural units scattered throughout the clot; the degree of structural disorganization depends on the extent of such incorporation. However, the final morphological appearance reflects two additional features secondary to inhibition of fibrin polymerization: 1) the arrested formation of fiber strands at a stage similar to that described by Porter and Hawn (21); and 2) as a consequence of the former, the subsequent formation of an abnormal gel.

\section{SUMMARY}

1. The ultrastructure of fibrin clots, formed in the presence of fibrinogen proteolysis products and prepared from either purified fibrinogen solution or plasma, has been investigated by electron microscopy.

2. Low concentrations of fibrinogen proteolysis products produced striking alterations in clot structure. These abnormalities included: inhibition of unit and compound fiber formation, the occurrence of blindly terminating fibers with either a tapering or "frayed rope" appearance, signs of markedly diminished lateral aggregation with partial failure of network formation, and the appearance of undifferentiated aggregates incorporated into the clot structure.

3. The findings indicate that fibrinogen proteolysis products inhibit clot formation occurring in plasma or in purified fibrinogen solutions. The observations provide a morphological counterpart for the consequences of defective fibrin polymerization and provide a basis for the occurrence of a hemorrhagic diathesis in patients suffering from pathological plasma proteolytic states.

\section{ACKNOWLEDGMENTS}

This investigation could neither have been undertaken nor completed without generous, unstinted help and advice from Dr. Sarah Luse and Dr. John Smith of Washington University School of Medicine and from Dr. Roger Hart of Washington University; Dr. Keith R. Porter of the Rockefeller Institute also provided valuable criticism. We are indebted to Mrs. Jean Bang and Mrs. Odessa Hill for technical assistance.

\section{REFERENCES}

1. Fletcher, A. P., Alkjaersig, N., and Sherry, S. Pathogenesis of the coagulation defect developing during pathological plasma proteolytic ("fibrinolytic") states. I. The significance of fibrinogen proteolysis and circulating fibrinogen breakdown products. J. clin. Invest. 1962, 41, 896.

2. Alkjaersig, N., Fletcher, A. P., and Sherry, S. Pathogenesis of the coagulation defect developing 
during pathological plasma proteolytic ("fibrinolytic") states. II. The significance, mechanism and consequences of defective fibrin polymerization. J. clin. Invest. 1962, 41, 917.

3. Fletcher, A. P., Alkjaersig, N., and Sherry, S. The maintenance of a sustained thrombolytic state in man. I. Induction and effects. J. clin. Invest. 1959, 38, 1096.

4. Niewiarowski, S., and Kowalski, E. Un nouvel anticoagulant dérivé du fibrinogène. Rev. Hémat. 1958, $13,320$.

5. Blomback, B., and Blomback. M. Purification of human and bovine fibrinogen. Ark. Kemi 1956, $10,415$.

6. Alkjaersig, N., Fletcher, A. P., and Sherry, S. The mechanism of clot dissolution by plasmin. J. clin. Invest. 1959, 38, 1086.

7. Alkjaersig, N., Fletcher, A. P., and Sherry, S. The activation of human plasminogen. II. A kinetic study of activation with trypsin, urokinase, and streptokinase. J. biol. Chem. 1958, 233, 86.

8. Porath, J. Fractionation of polypeptides and proteins on dextran gels. Clin. chim. Acta 1959, 4, 776.

9. Ratnoff, O. D., and Menzie, C. A new method for the determination of fibrinogen in small samples of plasma. J. Lab. clin. Med. 1951, 37, 316.

10. Palade, G. E. A study of fixation for electron microscopy. J. exp. Med. 1952, 95, 285.

11. Johnson, A. J., Fletcher, A. P., McCarty, W. R., and Tillett, W. S. The intravascular use of streptokinase. Ann. N. Y. Acad. Sci. 1957, 68, 201.

12. Alkjaersig, N., Fletcher, A. P., and Sherry, S.
$\epsilon$-Aminocaproic acid: An inhibitor of plasminogen activation. J. biol. Chem. 1959, 234, 832.

13. Sawyer, W. D., Fletcher, A. P., Alkjaersig, N., and Sherry, S. Studies on the thrombolytic activity of human plasma. J. clin. Invest. 1960, 39, 426.

14. Hawn, C. V. Z., and Porter, K. R. The fine structure of clots formed from purified bovine fibrinogen and thrombin: A study with the electron microscope. J. exp. Med. 1947, 86, 285.

15. Hall, C. E. Electron microscopy of fibrinogen and fibrin. J. biol. Chem. 1949, 179, 857.

16. Morrison, P. R., and Scudder, C. L. Fibrin clot structure during clotting as observed in unsupported films under electron microscope. Amer. J. Physiol. 1952, 170, 147.

17. Scheraga, H. A., and Laskowski, M., Jr. The fibrinogen-fibrin conversion. Advanc. Protein Chem. 1957, 12, 1.

18. Ferry, J. D., and Morrison, P. R. Preparation and properties of serum and plasma proteins. VIII. The conversion of human fibrinogen to fibrin under various conditions. J. Amer. chem. Soc. 1947, 69, 388.

19. Edsall, J. T., and Lever, W. F. Effect of ions and neutral molecules on fibrin clotting. J. biol. Chem. 1951, 191, 735.

20. Hall, C. E., and Slayter, H. S. The fibrinogen molecule: Its size, shape, and mode of polymerization. J. biophys. biochem. Cytol. 1959, 5, 11.

21. Porter, K. R., and Hawn, C. V. Z. Sequences in the formation of clots from purified bovine fibrinogen and thrombin: A study with the electron microscope. J. exp. Med. 1949, 90, 225. 